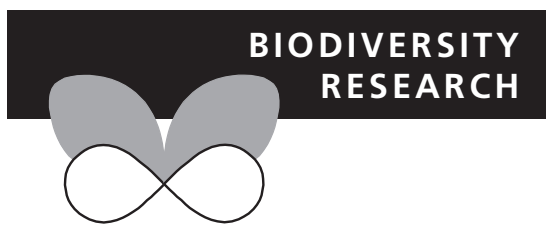

\title{
Testing for taxonomic bias in the future diversity of Australian Odonata
}

\author{
Alex Bush ${ }^{1 \star}$, David A. Nipperess ${ }^{1}$, Gunther Theischinger ${ }^{2,3}$, Eren Turak ${ }^{2,3}$ \\ and Lesley Hughes ${ }^{1}$
}

\begin{abstract}
${ }^{1}$ Macquarie University, Sydney, NSW, Australia, ${ }^{2}$ Office of Environment and Heritage NSW, Sydney, NSW, Australia, ${ }^{3}$ Australian Museum, 6 College Street, Sydney, NSW 2010, Australia
\end{abstract}

${ }^{*}$ Correspondence: Alex Bush, Department of Biological Sciences, Macquarie University, North Ryde, NSW 2109, Australia. E-mail: alexalbush@gmail.com

\section{ABSTRACT}

Aim Invertebrates are often overlooked in assessments of climate change impacts. Odonata (dragonflies and damselflies) are a significant component of freshwater macroinvertebrate diversity and are likely to be highly responsive to a changing climate. We investigate whether climate change could lead to significant alteration of continental patterns of diversity and whether vulnerable species are taxonomically clustered.

Location Australia.

Methods Habitat suitability of 270 odonate species was modelled, and a simplified phylogeny was developed based on taxonomic relationships and expert opinion. These maps were then combined to compare species richness, endemism, taxonomic diversity (TD) and taxonomic endemism (TE) under climate change scenarios, and estimate turnover in species composition. Based on the concentration of vulnerable species in regions associated with Gondwanan relicts, we tested the possibility that a focus on species loss would underestimate loss of evolutionary diversity.

Results Species richness of Australian Odonata is concentrated in the Wet Tropics, central-north Australia and south-east Queensland. Several additional regions support endemic assemblages, including the Victorian alpine region, the Pilbara and far south-western Australia. Major shifts in composition are expected across most of the east coast in response to climate change, and Tasmania has the potential to become a major refuge for mainland species. For many regions, the loss of TD is greater than expected based on the changes in species richness, and the loss of suitable habitat was unevenly distributed among families. However, the potential loss of evolutionary diversity among vulnerable species was not significantly different from random.

Main conclusions The major shifts in the distribution of Australian odonate diversity predicted to occur under climate change imply major challenges for conservation of freshwater biodiversity overall. Although major evolutionary losses may be avoided, climate change is still a serious threat to Australia's Odonata and poses an even greater threat to Australian freshwater biodiversity as a whole.

\section{Keywords}

Climate change, damselflies, dragonflies, endemism, phylogenetic diversity, refugia, richness, species distribution model, turnover.

\section{INTRODUCTION}

Freshwater ecosystems have become increasingly altered by human activities, and the decline in freshwater biodiversity over recent decades has been faster than in either terrestrial or marine ecosystems (Jenkins, 2003; WWF, 2012). The effects of extensive human modification of biodiversity will be exacerbated in the future by climate change (Palmer et al., 2008,2009 ) and significantly increase the prospect of major biodiversity loss (Xenopoulos et al., 2005; Bellard et al., 
2012). Across multiple species, the combination of shifting habitat suitability and novel interactions is predicted to significantly alter the composition of regional freshwater assemblages (e.g. Durance \& Ormerod, 2007; Chessman, 2009) and, where the opportunity to move to higher latitudes or altitudes is not available, the risk to species is likely to be high (Sauer et al., 2011). If climate change results in local or regional loss of sensitive (Hering et al., 2009) or dispersallimited species (Kappes \& Haase, 2012), the potential for a reduction in ecosystem stability and function increases (Cadotte et al., 2012; Mouillot et al., 2013).

Despite the dominance of invertebrates in aquatic communities, few studies of climate change impacts have been able to include invertebrate taxa due to taxonomic difficulties, the low availability of records and poor overall understanding of species ecology (Cardoso et al., 2011). A powerful first step in assessing vulnerability is to model the relationship between species occurrence and the environment using species distribution models (SDM, e.g. Diniz-Filho et al., 2009; Elith et al., 2010). Although several studies have shown SDMs can be applied to freshwater invertebrates (e.g. Domisch et al., 2012; Simaika et al., 2013), spatial assessments of climate change impacts are uncommon for these taxa, and this shortfall could bias the balance of recommendations for adaptation and protection (Darwall et al., 2011). There is also increasing pressure to consider genetically distinct species in conservation prioritisation in addition to rarity and threats (Moritz, 2002; Isaac et al., 2007). Phylogenetic diversity captures the evolutionary relations of species based on the sum of branch lengths, and this is also likely to reflect phenotypic and ecological similarities (Erwin, 1991; Hartmann \& André, 2013). By accounting for the evolutionary distinctiveness among species, we are more likely to conserve multiple unknown, and hard to measure, ecological traits (Crozier et al., 2005; Tucker et al., 2012).

In Australia, climate change is a major threat to freshwater biodiversity. Temperatures continue to rise, and there have been regional declines in rainfall and discharge (Lough \& Hobday, 2011; Hughes et al., 2012). Further declines in rainfall are projected in western and south-eastern Australia by 2055, with more variable projections in the north (Petheram et al., 2012; James et al., 2013). Australia's Odonata (dragonflies and damselflies) include many ancient lineages of Gondwanan origin, and most are thought to have become restricted to cooler climates and perennial freshwater habitats following periods of aridification that started approximately 20 Mya (Martin, 2006). Asian-origin odonates did subsequently colonize Australia and are now a large part of the fauna, including many of the vagrant and arid-zone-adapted species (Watson et al., 1991). Under climate change, the vulnerability of Australian Odonata (Bush et al., 2014) is strongly associated with regions containing Gondwanan refugia (Moritz, 2002; Krosch et al., 2009). Endemics of these regions are at greater risk of climate change impacts because they have evolved within narrower climatic boundaries (Hering et al., 2009; Calosi et al., 2010; Botts et al., 2013). We therefore suggest that a focus on the number of species vulnerable to climate change could underestimate the proportion of evolutionary diversity at risk if those species are predominantly from distinct Gondwanan lineages, and in some cases, families endemic to Australia (e.g. Hemiphlebiidae).

This study uses the modelled distribution of habitat for Australian Odonata to identify continental trends in diversity and how these patterns could change in the future as a result of climate change. We also specifically aimed to identify where the greatest overall change in odonate assemblages may occur, and whether those species at higher risk represent a taxonomically biased portion of the community, the loss of which could result in a significantly increased reduction in TD.

\section{METHODS}

\section{Species data and species distribution modelling}

Records of Australian odonates were compiled from the collections of all Australian museums, environmental agencies in four states (Queensland, New South Wales, Victoria and Western Australia), and all known private collectors. There were insufficient data available to model 37 species, and we also did not consider any species from countries outside Australia. We believe the likelihood of many species colonizing Australia under changing climates is low because the monsoon system appears to inhibit movement across the Coral Sea, evident in the low numbers of species shared between Australia and Papua New Guinea (Kalkman \& Orr, 2012).

An ensemble forecasting approach was used to account for uncertainty in modelling method (Jones-Farrand et al., 2011) based on five statistical algorithms: (1) generalized linear models, (2) generalized additive models, (3) boosted regression trees, (4) multivariate adaptive regression splines and (5) MaxEnt (Elith et al., 2006; Beaumont et al., in review). Analyses were implemented with the BIOMOD2 package (Thuiller et al., 2009) for the $\mathrm{R}$ statistical and programming environment ( $\mathrm{R}$ Core Team, 2013). Pseudo-absences for the models were selected from localities within a $300 \mathrm{~km}$ radius of observed occurrences at localities where other Odonata had also been recorded. The true skill statistic (TSS; Doswell et al., 1990) was used to weight models in the ensemble, and used to calculate a minimum threshold for species habitat suitability (Liu et al., 2013). Habitat suitability was projected onto maps of stream subcatchments across Australia derived from 250-m-square digital elevation models (GEOFABRIC, 2011). Projections included climatic, topographic and hydrological factors, and suitability was reduced when more than one predictive factor was outside the limits of the training data (Elith et al., 2011). Projections under current conditions were constrained to a $300 \mathrm{~km}$ radius from observed records, and extended under future climates based on a maximum dispersal rate of $15 \mathrm{~km} \mathrm{yr}^{-1}$ (Bush et al., 2014). Future 
climate scenarios were based on relative concentration pathways (RCPs) that describe emissions pathways in the forthcoming Fifth Assessment Report of the Intergovernmental Panel on Climate Change. We chose to use the higher scenarios (RCP6 and RCP8.5) because at present, these capture the most likely trajectories of emissions (Peters et al., 2013). Climate predictions for 2055 and 2085 were based on ensembles of seven global climate models that perform well in predicting Australian patterns of precipitation (Fordham et al., 2012). At the continental scale, the downscaled climate data available are independent of elevation and so projections in topographically complex terrain may suffer (Corney et al., 2010). Overall, the final data set contained the modelled distribution of suitable habitat for 270 Odonata in all Australian subcatchments under current and future climates. These subcatchment layers were split into 250-m-square blocks and reaggregated as $1-\mathrm{km}^{2}$ grids matching the resolution of the climate data so that the equal area assumptions of the analysis could be met.

\section{Richness and turnover}

The composition of local assemblages was inferred by aggregating species-level projections for all species (the 'predict first, assemble later' method of Ferrier and Guisan, 2006). Stacked species distribution models (S-SDMs) based on binary projections are likely to overestimate the number of species present in a community and so we used the suitability scores as weights to estimate richness (Calabrese et al., 2013; Rosauer \& Moritz, 2013). Richness was thus equivalent to the sum of suitable habitat scores for all species in a cell. Suitability scores from marginal habitats where that were below the TSS-based threshold were set to zero. Weighted endemism counts the same species weighted by the inverse of their range (e.g. Slatyer et al., 2007), calculated here as the sum of their habitat suitability scores (see also Rosauer \& Moritz, 2013). Turnover in this study was simply defined as the sum of species suitability scores lost and gained by a site from the present to a future climate scenario. This is the equivalent of defining turnover as $b+c$, where $b$ and $c$ are matching components commonly used in beta diversity indices (Koleff et al., 2003), and are the quantities unique to the present and future scenarios, respectively. We chose not to use indices such as a Jaccard or Bray-Curtis to compare turnover because they are proportional to richness (e.g. Carvalho et al., 2010), and this merely highlighted complete replacement in species-poor regions at the expense of much greater absolute change in diverse communities.

\section{Taxonomic diversity}

A molecular-based phylogeny was not available for Australian Odonata, but taxonomic hierarchies are considered reasonable surrogates of the information present in dated phylogenies (Crozier et al., 2005; Ricotta et al., 2012). We therefore constructed a phylogeny for Australian Odonata largely based on taxonomic divisions following the familial arrangement in Djikstra et al. (2013) (see Figs. S1 and S2 in Supporting Information). Additional taxonomic groups for Australian Odonata that have not yet been resolved within the global literature, including subfamilies, tribes or lower level units, were included from the relevant literature (Theischinger \& Watson, 1984; Watson \& Theischinger, 1984; Watson et al., 1991; Peters \& Theischinger, 2007; Theischinger \& Endersby, 2009; Theischinger, 2012) and several unpublished phylogenetic studies (G. Theischinger, pers. comm.). The purpose of this phylogeny is not to advance the systematic debate over relationships among Odonata (Ballare \& Ware, 2011), but to provide a basis for analytical comparison using the best available current knowledge. The tree was built in TREEMAKER v1.3 (Crozier et al., 2005) with branch lengths scaled as one for each change in taxonomic rank.

To complement the analysis of richness, endemism and turnover for species diversity, phylogenetic diversity (Faith, 1992), phylogenetic endemism (Rosauer et al., 2009) and phylogenetic turnover (Nipperess et al., 2010) were calculated based on the same principle, but using branch lengths as units of diversity, as opposed to species, and weighting presences according to suitability scores. We hereafter refer to these indices as TD and TE. TD counts the branches linking a set of taxa as a surrogate for unique or shared features represented by the taxa in the tree (Faith, 1992). TE is used to identify areas where substantial components of TD are restricted (Rosauer et al., 2009). The value of TE for taxa in a given area requires calculating the range size of each branch of the taxonomic tree (rather than the range of each taxon). TE is then the sum of branch lengths, each divided by the total range of its descendent species. TD turnover is calculated in an analogous way to that for species turnover where total branch length lost and gained is summed, and without standardizing according to overall diversity. This uses the same definition of absolute turnover $(b+c)$, with the phylogenetic equivalents defined by Nipperess et al. (2010), and substituting suitability score for abundance as the weighting.

Analysis of TD was performed in $\mathrm{R}$ using the ape package (Paradis et al., 2004) and the phylo.div and phylo.endemism functions (available from David Nipperess: http://davidnipperess.blogspot.com.au/). We tested whether families or genera explained a significant amount of change to a species' range (sum of their habitat suitability scores) using a mixed model in the lme4 package (Bates et al., 2012). We then tested for differences in the relative amount of TD in different groups of species assessed as being threatened by climate change (Bush et al., 2014, see Table S1). These included: (1) species predicted to lose all environmentally suitable habitat in 2085 using scenario RCP8.5 $(n=14)$, (2) highly vulnerable $(n=46)$, (3) and vulnerable species for the same scenario $(n=47)$, and (4) species poorly known and too rare to model $(n=37)$. The TD of $n$ vulnerable species was compared against a null model, which calculated the expected TD for $n$ randomly selected species drawn a thousand times 
from the total pool. The probability of the observed TD for a vulnerable species subset occurring by chance was calculated as the proportion of times the null model had an equal or higher TD than that observed. Finally, we compared whether differences in TD were approximately greater or less than might be expected for the given change in species richness by plotting the residuals of a linear regression between differences in TD (dependent variable) and richness (independent variable).

\section{RESULTS}

\section{Diversity}

Current species richness of Australian Odonata is predicted to be greatest in the north Queensland Wet Tropics, with potentially up to 92 species found in the region. Lesser 'hotspots' also occur in the far north of the Northern Territory, the tip of Cape York, south-east Queensland and north-east New South Wales (NSW) although there is reasonably high richness along most of the east coast (Figs $1 \& 2$ ). The richness hotspots also contain a high degree of endemism because each region has a distinct suite of species, but differences occur in some less diverse regions that contain their own restricted endemics such as small areas in the Pilbara and Kimberley in Northern-Western Australia, Carnarvon Gorge in central Queensland, the Grampians in western Victoria, western Tasmania and south-west Western Australia. The predicted distribution of TD is similar to that of species richness, but TD in Victoria and far south-western Australia is proportionally greater than expected for the number of

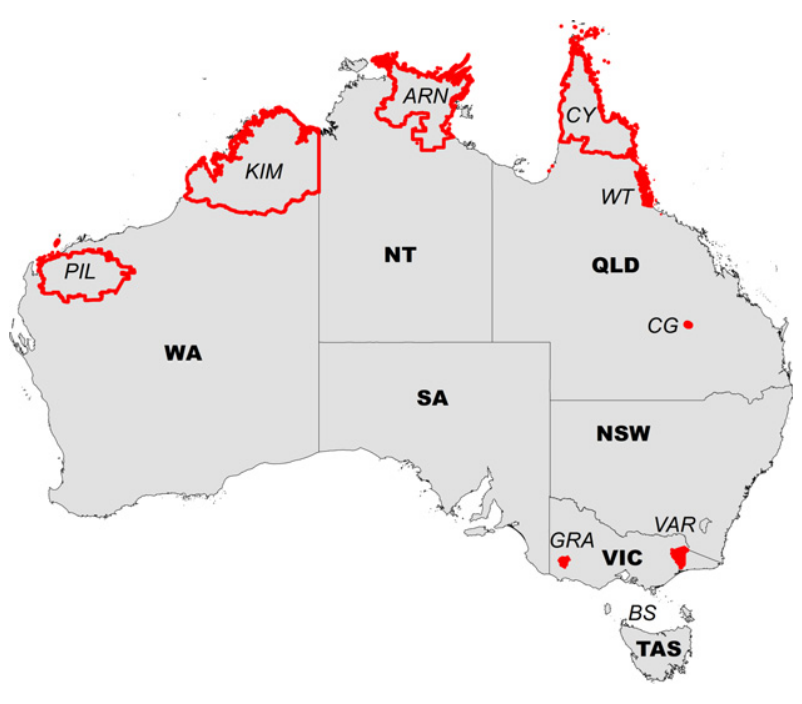

Figure 1 Australian states (bold): WA, Western Australia; NT, Northern Territory; SA, South Australia; Qld, Queensland; NSW, New South Wales; VIC, Victoria; TAS, Tasmania, and regions referred to in the main text (italics): PIL, Pilbara; KIM, Kimberly; ARN, Arnhem Land; CY, Cape York peninsula; WT, Wet Tropics; CG, Carnarvon Gorge; GRA, Grampians; VAR, Victorian Alpine Region; BS, Bass Strait. species, and the hotspot in south-east Queensland extends well into coastal NSW. High TE indicates that a site contains a large proportion of the range of those evolutionary lineages present. The current predicted distribution of TE was closely related to that of weighted endemism with a slightly greater concentration in southern regions like the Victorian alpine region and Tasmania.

Species richness is expected to decline in each of richness hotspots under current conditions, with nearly all species potentially lost from the far tropical northwest of the Northern Territory by 2085. Many of these species could significantly expand their current range under climate change, but the gains are partially lost again under the RCP8.5 scenario by 2085. Species richness is predicted to increase along the east of the Cape York Peninsula, and along the coasts and highlands of NSW, Victoria and South Australia. Assuming species are able to track suitable habitat and cross the Bass Strait, the richness of Tasmania could also double in the future. Potential loss of endemic species in the Pilbara, north Northern Territory and Carnarvon Gorge is projected. Changes in TD resemble the change in species richness but the balance of TD gains and losses varies among regions. Gain in TD along the east of the Cape York Peninsula, NSW coast and Tasmania is lower than expected for the given gains in species richness, and in the Pilbara, Wet Tropics and south-east Queensland in particular, the loss of TD is significantly higher than expected for the decline in species richness (Fig. 3). Changes to TE are more difficult to interpret because it is affected by both the number of species predicted to be present, and by the extent of their suitable habitat, but overall the trends follow changes in endemism. The magnitude of change increased from RCP6 to RCP8.5 emissions scenarios projections, but the patterns of changes were very similar.

\section{Turnover}

Under both RCP6 and RCP8.5 emissions scenarios, shifts in assemblage composition by 2055 are confined to small areas of the north and east coast, but by 2085 suitable habitat shifts south for large numbers of species along the east coast of Australia (Fig. 4a, b). A few small regions of the north in the Kimberley and Arnhem Land are also predicted to see significant changes, mostly as a result of species immigration from the hotspots on the north coast. Turnover is primarily driven by local extinction in the far north of Australia and gains in the south such as in Tasmania. In southern coastal NSW, the high turnover is a combination of local extinction and immigration that is equivalent to the current regional species richness. The absolute turnover of TD (Fig. 4c, d), based on the combined gains and losses of branches over time, is always higher than species turnover because changes in a single species can affect multiple branches. High-TD turnover extends from south-east Queensland to south-east NSW and is also proportionally higher than expected by 


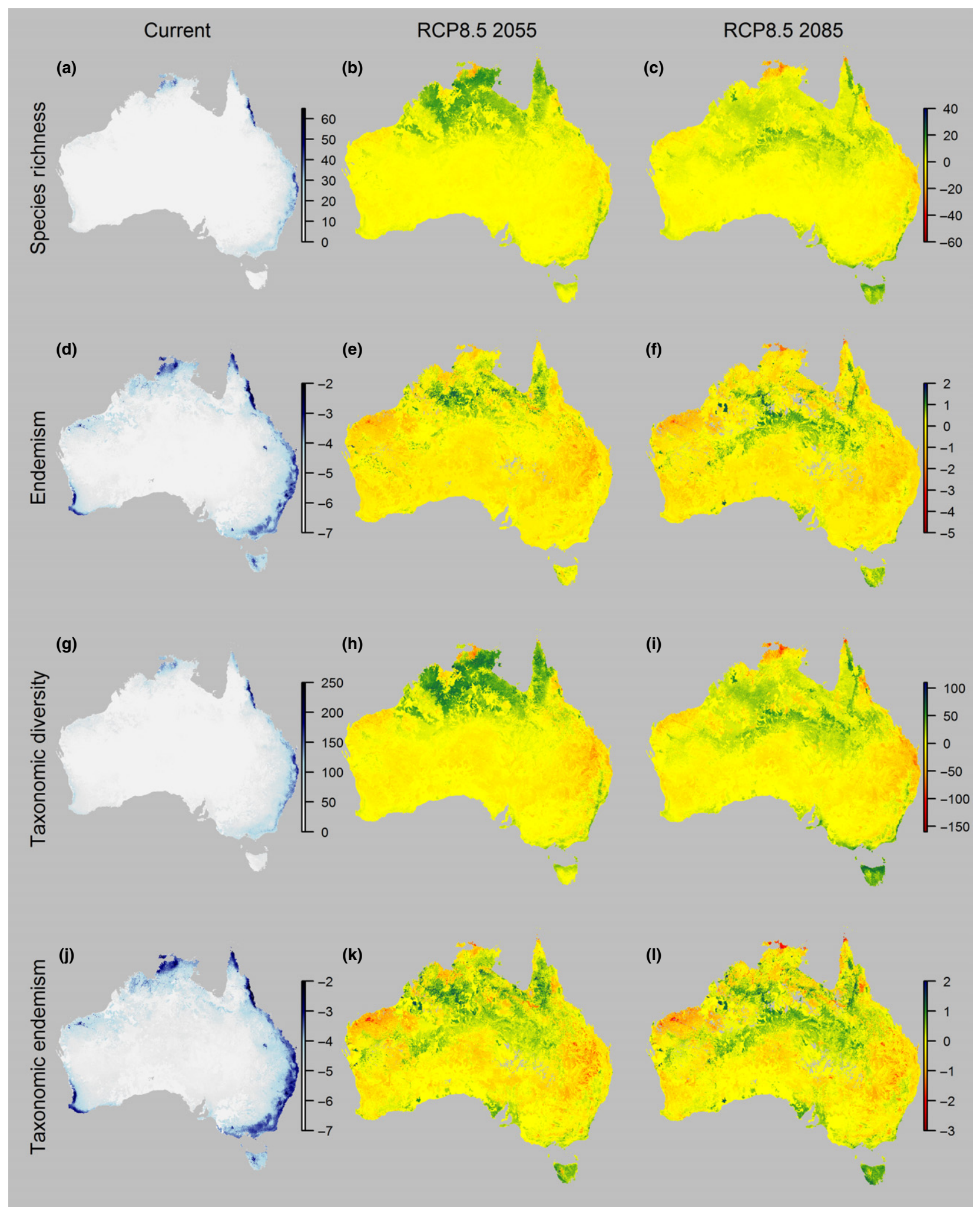

Figure 2 Australian Odonata richness, endemism, taxonomic diversity (TD) and taxonomic endemism (TE), under current climatic conditions (high values in blue), and the predicted change by 2055 and 2085 under emissions scenario relative concentration pathway (RCP) 8.5 (increases in green, and decreases in red). Richness and TD represent the sum of suitability values across all species or taxonomic branches. Endemism and TE are displayed on a log scale and represent the local suitability for a species or taxonomic branch divided by the total of their habitat suitability scores, summed across all species. 
Figure 3 Changes in odonate taxonomic diversity (TD) relative to changes in species richness (SR) from the current climate to the relative concentration pathway (RCP8.5) 2085 scenario, where richness is predicted to (a) increase and (b) decrease. Dark red and blue regions would have less TD than expected based on the change in SR, whereas yellow regions have higher TD given the change in SR.
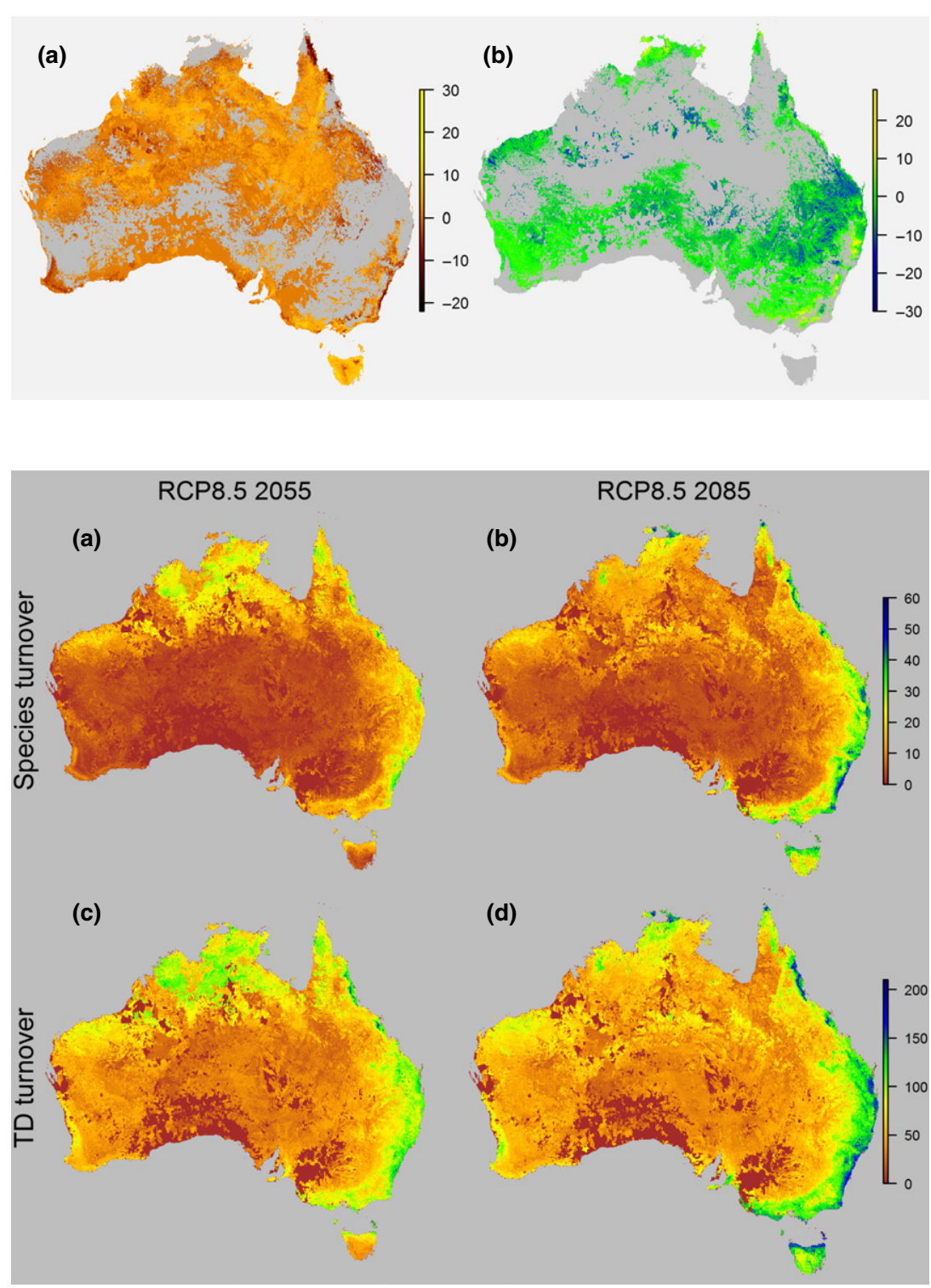

Figure 4 Predicted turnover defined as the combined gains and losses in habitat suitability of species ( $a$ and b), or of taxonomic branches (c and d) for Australian odonate assemblages between the current climate and the future climate in 2055 and 2085 (scenario relative concentration pathway (RCP8.5). The greatest turnover is in blue.

from species turnover in northern Tasmania and south-western Australia.

\section{Evolutionary bias among threatened Odonata}

In addition to spatial variation in the distribution of diversity shifts, there was significant variation in the overall range shifts of species depending on their family and genus $(\triangle \mathrm{AIC}=3.0)$. Genus explained $14 \%$ of the variation in range size (total suitability), and family explained 6\%. Families such as Libellulidae, Aeshnidae and Corduliidae increased their range on average whereas others like Lestoideidae, Synlestidae and Gondwanan Aeshnidae declined. Platycnemidae was the most adversely affected with 10 of 11 species predicted to decline. Despite the variation in overall outcomes for families and genera, the TD of species threatened with extinction $(P=0.25)$, highly vulnerable $(P=0.67)$, or at high risk due to climate change $(P=0.37)$, or too rare to be modelled using SDMs $(P=0.78)$, was not significantly greater than a random selection (Fig. 5). Therefore, the species lost and threatened by climate change are not predicted to be biased towards more distinct evolutionary lineages and are unlikely to result in an exaggerated loss of evolutionary diversity.

\section{DISCUSSION}

This study indicates that dramatic changes in the distribution of suitable habitats for Australian Odonata may occur this century, particularly in present-day 'hotspots' of species richness. In addition, significant turnover may extend across almost the entire east coast. Vulnerable assemblages in the Pilbara, south-western Australia and Tasmania contain a high proportion of endemic species. If species are able to track suitable habitats and cross Bass Strait, Tasmania could become an important refuge for mainland species. Although there is a coarse taxonomic bias in threat from climate change, and a spatial mismatch between the change in TD 

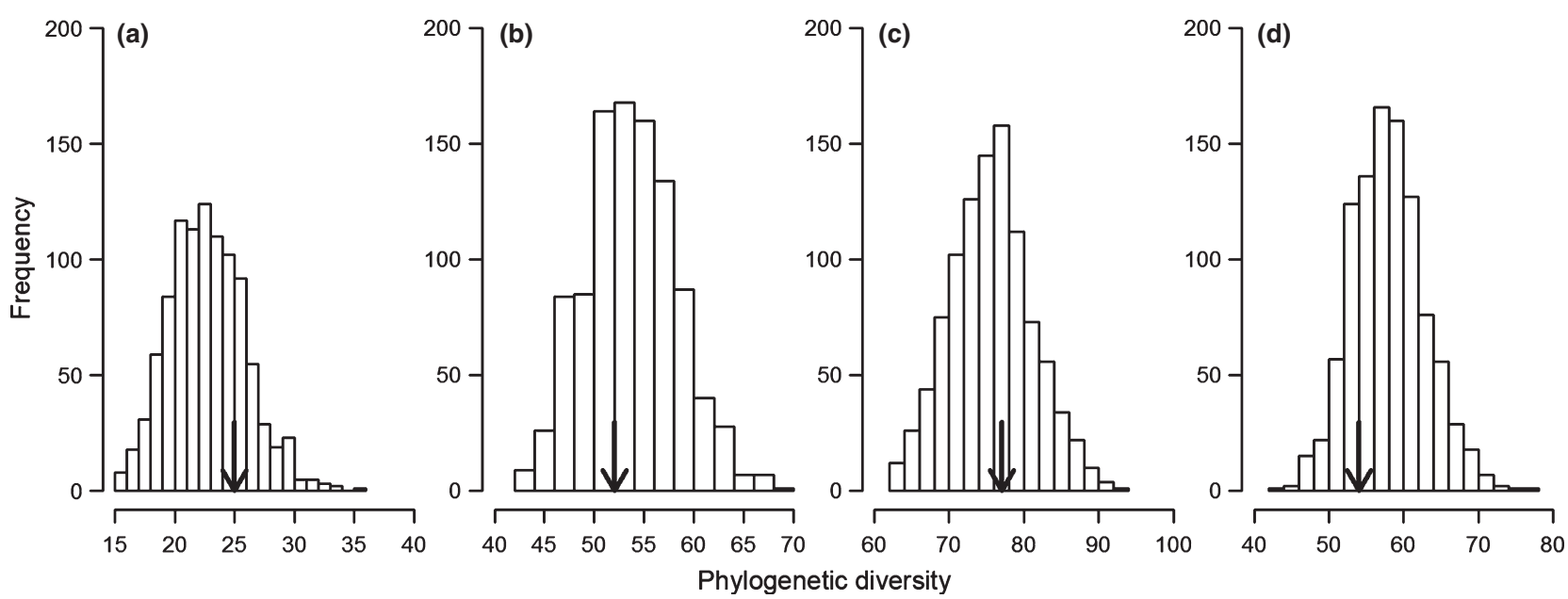

Figure 5 Distribution of taxonomic diversity (TD) for 1000 random subsets of $n$ Australian Odonata, equivalent to species threatened with (a) extinction $(P=0.25)$, or $(b)$ highly vulnerable $(P=0.67)$, or $(c)$ at high risk to climate change $(P=0.37)$ and $(d)$ rare species whose distribution has not been modelled $(P=0.78)$. Arrows indicate the TD for the threatened species.

and species richness, we did not find evidence that species most vulnerable in the future represent a greater than average proportion of evolutionary diversity at the continental scale.

\section{Richness}

Odonata have been the focus of several large-scale modelling studies, either to help prioritize continental conservation targets (Simaika et al., 2013) or to estimate gaps in sampling effort (Hassall, 2011). Odonates are well suited to SDM studies because they are particularly responsive to climatic factors (Hassall \& Thompson, 2008), and have strong aerial dispersal which means spatial changes in assemblage composition and richness are predominantly driven by environmental changes (Bush et al., 2013; Heino, 2013). Australian Odonata have previously been identified as showing a strong latitudinal gradient in species richness (Boulton et al., 2005; Pearson \& Boyero, 2009), but given the high richness of south-east Queensland (subtropical) and New South Wales (temperate), our study does not support this. We did not attempt to associate patterns of diversity of species with environmental factors because these factors would not have been independent of the variables used to model individual species distributions. However, it does seem likely that the richness of Odonata in Australia is driven by a water-energy balance in the environment (Keil et al., 2008), with particularly rich assemblages found in regions that support rain forest (Clausnitzer et al., 2009).

It is important to understand that the SDM outputs assume a species is present throughout all suitable habitats and overlaying them to estimate richness and composition is predisposed to include errors of commission and overestimate richness (Guisan \& Rahbek, 2011; Pineda \& Lobo, 2012). Species could be absent or uncommon at sites that are predicted to be environmentally suitable due to dispersal constraints, biotic interactions, unsuitable micro-habitats and stochastic effects (Heikkinen et al., 2006) or human habitat modification (Mangiacotti et al., 2013). For example, SDMs predicted 26 species could occur at Middle Creek in Victoria where Hawking and New (2002) sampled odonates (larvae and adults) intensively on 20 visits over three years. They found fine-scale patterns in sediment composition affected species composition, allowing 18 species to occur in the creek, four more in the nearby river and at least nine more in the surrounding area (Hawking \& New, 1999), including all those species predicted by the models. The relationship between local and regional species richness could have been used to modify estimates, but there were few locations in Australia with the required intensity of sampling to model richness directly (Gotelli et al., 2009).

\section{Endemism and TD}

Understanding the relationship of threatened species within communities has become increasingly important as the need to prioritize conservation effort seeks to emphasize the most evolutionarily distinct species (Isaac et al., 2007; Tucker et al., 2012). Furthermore, high regional endemism indicates the overlap of species with restricted ranges that are more likely to have narrower environmental tolerances, and be threatened by climate change (Calosi et al., 2010). Distinct regional assemblages are evident in Tasmania, and in the Pilbara which is increasingly recognized as a centre of invertebrate endemism (Pinder et al., 2010). Many endemic Odonata are found in south-western Australia, a similar pattern to that in the flora (Davies \& Stewart, 2013). These species represent proportionally more TD than just species richness would suggest (Sander \& Wardell-Johnson, 2011). The rain forests of the Wet Tropics are both species rich and taxonomically diverse, but the region is highly threatened by climate change (Hughes, 2011; James et al., 2013), and the mismatch between loss of species and decrease in TD demonstrates that the more evolutionarily distinct species are under threat in this region. 
Although there were broad biases among odonate families, the groups of species considered vulnerable were not a significantly diverse evolutionary subset of Australian Odonata (Thuiller et al., 2011). Naturally, this depends on whether the taxonomic hierarchy is congruent with a molecular phylogeny that can both resolve the many polytomies and improve the estimation of branch lengths. For example, some of the basal polytomies among odonate families could mean TD is more likely to be underestimated (Swenson, 2009). Ricotta et al. (2012) found a strong correlation between dated phylogenies and taxonomic hierarchy, suggesting that at least, the relative distribution of TD/TE is likely to remain similar. Whether the diversity of vulnerable species was in fact higher is difficult to judge, but given the results were not marginal and species from monotypic families were not threatened, a fully resolved phylogeny would have to significantly alter perceived relationships to reverse this result. Nonetheless, we should be aware the loss of TD associated with species vulnerable to climate change would be a significant loss from a conservation perspective and there are also likely to be further losses of genetic diversity within species, with unknown consequences for population resilience (Balint et al., 2011).

\section{Turnover}

Although loss of species in distinct and endemic regional faunas is a major concern, the implications of high turnover in response to climate change are an even more serious challenge for many other freshwater taxa (Heino, 2011; Turak et al., 2011). We assume Odonata will be able to track at least some of the predicted shift in habitat suitability to higher latitudes because they are relatively strong flyers (e.g. Hickling et al., 2006). Those species unable to fly, however, will face dispersal difficulties because most river basins along the Australian east coast are oriented from west to east ( $\mathrm{Tu}-$ rak et al., 2011; Bush et al., 2012). Even among Odonata, some species can be dispersal limited (Hassall \& Thompson, 2012) and may not be able to reach all suitable habitats under changing climates (Jaeschke et al., 2012). For example, aside from the Bass Strait, there are several gaps along the Great Dividing Range that suggest odonate species diverged according to breaks in the terrain (Watson \& Theischinger, 1984). Even if species can disperse to climatically suitable regions, it may not ensure successful establishment (Angert et al., 2011), resident species could competitively exclude new arrivals or alternatively, climate change may provide immigrant species with a competitive advantage, displacing resident species (Suhling \& Suhling, 2013). However, research in Victoria has shown the relationship between local and regional richness of macroinvertebrates appears to be linear, suggesting communities are not necessarily saturated, and could accept immigrant species (Marchant et al., 2006). Overall, we might therefore expect most Odonata to follow predicted range shifts, the more significant projected increases in richness should be interpreted with caution, for regions such as Tasmania which is $220 \mathrm{~km}$ from the mainland.

The capacity for altitudinal migration is limited in most catchments (Sauer et al., 2011), and headwaters are also less likely to sustain flows during droughts (Robson et al., 2011). Many species are already isolated on mountain ranges, in climatic cul de sacs from which they cannot disperse across lowlands to other refugia (Hughes et al., 2009). Regions that retain suitable habitat for the greatest number of species under climate change could be conservation targets for freshwater focal areas (Abell et al., 2007), but this also requires critical management zones to safeguard these habitats in the long term by managing the riparian corridor and landscape upstream (Davies, 2010). Promoting connectivity with focal refugia is essential, and those with high turnover could act as useful transition areas for multiple species over time (e.g. Phillips et al., 2008). Habitat connections can serve multiple species, and connectivity is best viewed in conjunction with terrestrial conservation as part of a single holistic strategy. In the case of truly aquatic and dispersal-limited species, managed translocation may have to be considered (Morrongiello et al., 2011). Rugged terrain could provide sufficient resilience to safeguard vulnerable species in regions like the Wet Tropics (Luoto \& Heikkinen, 2008), but as elsewhere, this depends on the capacity of species to reach suitable habitats (Krosch et al., 2009).

In contrast to many other macroinvertebrate orders, odonates are typically thermophilic, strong dispersers and generalist predators, traits that improve their adaptive capacity under climate change (Hassall \& Thompson, 2008; Williams et al., 2008). Conversely, a large number of other aquatic macroinvertebrates are sensitive to temperature increases, or are slow to recover following reductions in flow and are potentially more susceptible to the effects of climate change than Odonata (Hering et al., 2009; Belmar et al., 2012). Other freshwater taxa such as fish, molluscs and crustaceans may be at even greater risk if they are sensitive to change but cannot disperse to climatically suitable habitats (Buisson et al., 2012; Kappes \& Haase, 2012; James et al., 2013). Previous research on whole-community studies suggests that climate change will result in dramatic changes to macroinvertebrate assemblage structure and ecosystem dynamics (Daufresne et al., 2007; Thompson et al., 2013), and this will have consequences for primary productivity and organic matter processing, that in turn support diversity and abundance of higher consumers (e.g. Mulholland et al., 2001). Therefore, where possible, trait data should guide conservation priorities to sustain ecosystem function under climate change (e.g. Bonada et al., 2007; Mouillot et al., 2013), and in their absence, TD is likely to provide the most practical criterion for preserving functional diversity.

\section{ACKNOWLEDGEMENTS}

We thank Klaas-Douwe Dijkstra and Vincent Kalkman for providing their expertise on Odonata phylogeny. 


\section{REFERENCES}

Abell, R., Allan, J.D. \& Lehner, B. (2007) Unlocking the potential of protected areas for freshwaters. Biological Conservation, 134, 48-63.

Angert, A.L., Crozier, L.G., Rissler, L.J., Gilman, S.E., Tewksbury, J.J. \& Chunco, A.J. (2011) Do species' traits predict recent shifts at expanding range edges? Ecology Letters, 14, 677-689.

Balint, M., Domisch, S., Engelhardt, C.H.M., Haase, P., Lehrian, S., Sauer, J., Theissinger, K., Pauls, S.U. \& Nowak, C. (2011) Cryptic biodiversity loss linked to global climate change. Nature Climate Change, 1, 313-318.

Ballare, E.F. \& Ware, J.L. (2011) Dragons fly, biologists classify: an overview of molecular odonate studies, and our evolutionary understanding of dragonfly and damselfly (Insecta: Odonata) behavior. International Journal of Odonatology, 14, 137-147.

Bates, D., Maechler, M. \& Bolker, B. (2012) lme4: linear mixed-effects models using S4 classes. $\mathrm{R}$ package version 1.0-5.

Beaumont, L., Duursma, D., Wilson, P.D., Cabrelli, A., Thuiller, W., VanDerWal, J. \& Williams, S. (in review) Which species distribution models are more (or less) likely to project broad-scale, climate-induced shifts in species ranges?

Bellard, C., Bertelsmeier, C., Leadley, P., Thuiller, W. \& Courchamp, F. (2012) Impacts of climate change on the future of biodiversity. Ecology Letters, 15, 365-377.

Belmar, O., Velasco, J., Gutiérrez-Cánovas, C., Mellado-Díaz, A., Millán, A. \& Wood, P.J. (2012) The influence of natural flow regimes on macroinvertebrate assemblages in a semiarid Mediterranean basin. Ecohydrology, 6, 363-379.

Bonada, N., Dolédec, S. \& Statzner, B. (2007) Taxonomic and biological trait differences of stream macroinvertebrate communities between mediterranean and temperate regions: implications for future climatic scenarios. Global Change Biology, 13, 1658-1671.

Botts, E.A., Erasmus, B.F.N. \& Alexander, G.J. (2013) Small range size and narrow niche breadth predict range contractions in South African frogs. Global Ecology and Biogeography, 22, 567-576.

Boulton, A.J., Boyero, L., Covich, A.P., Dobson, M.K., Lake, P.S. \& Pearson, R.G. (2005) Are tropical streams ecologically different from temperate streams?. Academic Press, San Diego. Buisson, L., Grenouillet, G., Villéger, S., Canal, J. \& Laffaille, P. (2012) Toward A Loss Of Functional Diversity In Stream Fish Assemblages Under Climate Change. Global Change Biology, 19, 387-400.

Bush, A., Nipperess, D., Turak, E. \& Hughes, L. (2012) Determining vulnerability of stream communities to climate change at the landscape scale. Freshwater Biology, 57, 1689-1701.

Bush, A., Theischinger, G., Nipperess, D., Turak, E. \& Hughes, L. (2013) Dragonflies: climate canaries for river management. Diversity and Distributions, 19, 86-97.

Bush, A., Nipperess, D.A., Duursma, D., Theischinger, G., Turak, E. \& Hughes, L. (2014) Continental-scale assess- ment of risk to the Australian Odonata from climate change. PLoS ONE, 9, e88958.

Cadotte, M.W., Dinnage, R. \& Tilman, D. (2012) Phylogenetic diversity promotes ecosystem stability. Ecology, 93, S223-S233.

Calabrese, J.M., Certain, G., Kraan, C. \& Dormann, C.F. (2013) Stacking species distribution models and adjusting bias by linking them to macroecological models. Global Ecology and Biogeography, 23, 99-112.

Calosi, P., Bilton, D.T., Spicer, J.I., Votier, S.C. \& Atfield, A. (2010) What determines a species' geographical range? Thermal biology and latitudinal range size relationships in European diving beetles (Coleoptera: Dytiscidae). Journal of Animal Ecology, 79, 194-204.

Cardoso, P., Erwin, T.L., Borges, P.A.V. \& New, T.R. (2011) The seven impediments in invertebrate conservation and how to overcome them. Biological Conservation, 144, 2647-2655.

Carvalho, S.B., Brito, J.C., Crespo, E.J. \& Possingham, H.P. (2010) From climate change predictions to actions - conserving vulnerable animal groups in hotspots at a regional scale. Global Change Biology, 16, 3257-3270.

Chessman, B.C. (2009) Climatic changes and 13-year trends in stream macroinvertebrate assemblages in New South Wales, Australia. Global Change Biology, 15, 2791-2802.

Clausnitzer, V., Kalkman, V.J., Ram, M., Collen, B., Baillie, J.E.M., Bedjanič, M., Darwall, W.R.T., Dijkstra, K.D.B., Dow, R., Hawking, J., Karube, H., Malikova, E., Paulson, D., Schütte, K., Suhling, F., Villanueva, R.J., von Ellenrieder, N. \& Wilson, K. (2009) Odonata enter the biodiversity crisis debate: the first global assessment of an insect group. Biological Conservation, 142, 1864-1869.

Corney, S.P., Katzfey, J.J., McGregor, J.L., Grose, M.R., Bennett, J.C., White, C.J., Holz, G.K., Gaynor, S.M. \& Bindoff, N.L. (2010) Climate Futures for Tasmania: Climate modelling technical report. In. Antarctic Climate \& Ecosystems Cooperative Research Centre, Hobart, Tasmania.

Crozier, R.H., Dunnett, L.J. \& Agapow, P. (2005) Phylogenetic biodiversity assessment based on systematic nomenclature. Evolutionary Bioinformatics Online, 1, 11-36.

Darwall, W.R.T., Holland, R.A., Smith, K.G., Allen, D., Brooks, E.G.E., Katarya, V., Pollock, C.M., Shi, Y., Clausnitzer, V., Cumberlidge, N., Cuttelod, A., Dijkstra, K.-D.B., Diop, M.D., García, N., Seddon, M.B., Skelton, P.H., Snoeks, J., Tweddle, D. \& Vié, J.-C. (2011) Implications of bias in conservation research and investment for freshwater species. Conservation Letters, 4, 474-482.

Daufresne, M., Bady, P. \& Fruget, J.F. (2007) Impacts of global changes and extreme hydroclimatic events on macroinvertebrate community structures in the French Rhône River. Oecologia, 151, 544-559.

Davies, P.M. (2010) Climate change implications for river restoration in global biodiversity hotspots. Restoration Ecology, 18, 261-268.

Davies, P. \& Stewart, B. (2013) Aquatic biodiversity in the Mediterranean climate rivers of southwestern Australia. Hydrobiologia, 719, 215-235. 
Diniz-Filho, J.A.F., Mauricio Bini, L., Fernando Rangel, T., Loyola, R.D., Hof, C., Nogués-Bravo, D. \& Araújo, M.B. (2009) Partitioning and mapping uncertainties in ensembles of forecasts of species turnover under climate change. Ecography, 32, 897-906.

Djikstra, K.D.B., Bechly, G., Bybee, S.M., Dow, R., Dumont, H.J., Fleck, G., Garrison, R.W., Hämäläinen, M., Kalkman, V.J., Karube, H., May, M.L., Orr, A.G., Paulson, D.R., Rehn, A.C., Theischinger, G., Trueman, J.W.H., van Tol, J., von Ellenrieder, N. \& Ware, J.L. (2013) The classification and diversity of dragonflies and damselflies (Odonata). Zootaxa, 3703, 36-45.

Domisch, S., Araújo, M.B., Bonada, N., Pauls, S.U., Jähnig, S.C. \& Haase, P. (2012) Modelling distribution in European stream macroinvertebrates under future climates. Global Change Biology, 19, 752-762.

Doswell, C.A., Daviesjones, R. \& Keller, D.L. (1990) On summary measures of skill in rare event forecasting based on contingency tables. Weather and Forecasting, 5, 576-585.

Durance, I. \& Ormerod, S.J. (2007) Climate change effects on upland stream macroinvertebrates over a 25-year period. Global Change Biology, 13, 942-957.

Elith, J., Graham, C.H., Anderson, R.P. et al. (2006) Novel methods improve prediction of species' distributions from occurrence data. Ecography, 29, 129-151.

Elith, J., Kearney, M. \& Phillips, S. (2010) The art of modelling range-shifting species. Methods in Ecology and Evolution, 1, 330-342.

Elith, J., Phillips, S.J., Hastie, T., Dudík, M., Chee, Y.E. \& Yates, C.J. (2011) A statistical explanation of MaxEnt for ecologists. Diversity and Distributions, 17, 43-57.

Erwin, T.L. (1991) An evolutionary basis for conservation strategies. Science, 253, 750-752.

Faith, D.P. (1992) Conservation evaluation and phylogenetic diversity. Biological Conservation, 61, 1-10.

Ferrier, S. \& Guisan, A. (2006) Spatial modelling of biodiversity at the community level. Journal of Applied Ecology, 43, 393-404.

Fordham, D.A., Wigley, T.M.L., Watts, M.J. \& Brook, B.W. (2012) Strengthening forecasts of climate change impacts with multi-model ensemble averaged projections using MAGICC/SCENGEN 5.3. Ecography, 35, 4-8.

GEOFABRIC (2011) Australian hydrological geospatial fabric data product specification - surface network version 1.1.3. (ed. by Bureau of Meteorology). Available at: http://www. bom.gov.au/water/geofabric/.

Gotelli, N.J., Anderson, M.J., Arita, H.T. et al. (2009) Patterns and causes of species richness: a general simulation model for macroecology. Ecology Letters, 12, 873-886.

Guisan, A. \& Rahbek, C. (2011) SESAM - a new framework integrating macroecological and species distribution models for predicting spatio-temporal patterns of species assemblages. Journal of Biogeography, 38, 1433-1444.

Hartmann, K. \& André, J. (2013) Should evolutionary history guide conservation? Biodiversity and Conservation, 22, 449-458.
Hassall, C. (2011) Predicting the distributions of underrecorded Odonata using species distribution models. Insect Conservation and Diversity, 5, 192-201.

Hassall, C. \& Thompson, D.J. (2008) The effects of environmental warming on Odonata: a review. International Journal of Odonatology, 11, 131-153.

Hassall, C. \& Thompson, D.J. (2012) Study design and mark-recapture estimates of dispersal: a case study with the endangered damselfly Coenagrion mercuriale. Journal of Insect Conservation, 16, 111-120.

Hawking, J.H. \& New, T.R. (1999) The distribution patterns of dragonflies (Insecta: Odonata) along the Kiewa River, Australia, and their relevance in conservation assessment. Hydrobiologia, 392, 249-260.

Hawking, J.H. \& New, T.R. (2002) Interpreting dragonfly diversity to aid in conservation assessment: lessons from the Odonata assemblage at Middle Creek, north-eastern Victoria, Australia. Journal of Insect Conservation, 6, 171178.

Heikkinen, R.K., Luoto, M., Araújo, M.B., Virkkala, R., Thuiller, W. \& Sykes, M.T. (2006) Methods and uncertainties in bioclimatic envelope modelling under climate change. Progress in Physical Geography, 30, 751-777.

Heino, J. (2011) A macroecological perspective of diversity patterns in the freshwater realm. Freshwater Biology, 56, 1703-1722.

Heino, J. (2013) Does dispersal ability affect the relative importance of environmental control and spatial structuring of littoral macroinvertebrate communities? Oecologia, 171, 971-980.

Hering, D., Schmidt-Kloiber, A., Murphy, J., Lücke, S., Zamora-Muñoz, C., López-Rodríguez, M.J., Huber, T. \& Graf, W. (2009) Potential impact of climate change on aquatic insects: a sensitivity analysis for European caddisflies (Trichoptera) based on distribution patterns and ecological preferences. Aquatic Sciences, 71, 3-14.

Hickling, R., Roy, D.B., Hill, J.K., Fox, R. \& Thomas, C.D. (2006) The distributions of a wide range of taxonomic groups are expanding polewards. Global Change Biology, 12, 450-455.

Hughes, L. (2011) Climate change and Australia: key vulnerable regions. Regional Environmental Change, 11, 189-195.

Hughes, J.M., Schmidt, D.J. \& Finn, D.S. (2009) Genes in streams: using DNA to understand the movement of freshwater fauna and their riverine habitat. BioScience, 59, 573-583.

Hughes, J.D., Petrone, K.C. \& Silberstein, R.P. (2012) Drought, groundwater storage and stream flow decline in southwestern Australia. Geophysical Research Letters, 39, L03408.

Isaac, N.J., Turvey, S.T., Collen, B., Waterman, C. \& Baillie, J.E. (2007) Mammals on the EDGE: conservation priorities based on threat and phylogeny. PLOS ONE, 2, 1-7.

Jaeschke, A., Bittner, T., Reineking, B. \& Beierkuhnlein, C. (2012) Can they keep up with climate change? - Integrating specific dispersal abilities of protected Odonata in spe- 
cies distribution modelling. Insect Conservation and Diversity, 6, 93-103.

James, C., VanDerWal, J., Capon, S., Hodgson, L., Waltham, N., Ward, D., Anderson, B. \& Pearson, R. (2013) Identifying climate refuges for freshwater biodiversity across Australia. p. 150. National Climate Change Adaptation Research Facility, Gold Coast.

Jenkins, M. (2003) Prospects for Biodiversity. Science, 302, 1175-1177.

Jones-Farrand, D.T., Fearer, T.M., Thogmartin, W.E., Iii, F.R.T., Nelson, M.D. \& Tirpak, J.M. (2011) Comparison of statistical and theoretical habitat models for conservation planning: the benefit of ensemble prediction. Ecological Applications, 21, 2269-2282.

Kalkman, V.J. \& Orr, A.G. (2012) The Australian monsoon tropics as a barrier for exchange of dragonflies (Insecta: Odonata) between New Guinea and Australia. Hydrobiologia, 693, 55-70.

Kappes, H. \& Haase, P. (2012) Slow, but steady: dispersal of freshwater molluscs. Aquatic Sciences - Research Across Boundaries, 74, 1-14.

Keil, P., Simova, I. \& Hawkins, B.A. (2008) Water-energy and the geographical species richness pattern of European and North African dragonflies (Odonata). Insect Conservation and Diversity, 1, 142-150.

Koleff, P., Gaston, K.J. \& Lennon, J.J. (2003) Measuring beta diversity for presence-absence data. Journal of Animal Ecology, 72, 367-382.

Krosch, M.N., Baker, A.M., McKie, B.G., Mather, P.B. \& Cranston, P.S. (2009) Deeply divergent mitochondrial lineages reveal patterns of local endemism in chironomids of the Australian Wet Tropics. Austral Ecology, 34, 317-328.

Liu, C., White, M. \& Newell, G. (2013) Selecting thresholds for the prediction of species occurrence with presence-only data. Journal of Biogeography, 40, 778-789.

Lough, J.M. \& Hobday, A.J. (2011) Observed climate change in Australian marine and freshwater environments. Marine and Freshwater Research, 62, 984-999.

Luoto, M. \& Heikkinen, R.K. (2008) Disregarding topographical heterogeneity biases species turnover assessments based on bioclimatic models. Global Change Biology, 14, 483-494.

Mangiacotti, M., Scali, S., Sacchi, R., Bassu, L., Nulchis, V. \& Corti, C. (2013) Assessing the spatial scale effect of anthropogenic factors on species distribution. PLoS ONE, 8, e67573.

Marchant, R., Ryan, D. \& Metzeling, L. (2006) Regional and local species diversity patterns for lotic invertebrates across multiple drainage basins in Victoria. Marine and Freshwater Research, 57, 675-684.

Martin, H.A. (2006) Cenozoic climatic change and the development of the arid vegetation in Australia. Journal of Arid Environments, 66, 533-563.

Moritz, C. (2002) Strategies to Protect Biological Diversity and the Evolutionary Processes That Sustain It. Systematic Biology, 51, 238-254.
Morrongiello, J.R., Beatty, S.J., Bennett, J.C., Crook, D.A., Ikedife, D.N.E.N., Kennard, M.J., Kerezsy, A., Lintermans, M., McNeil, D.G., Pusey, B.J. \& Rayner, T. (2011) Climate change and its implications for Australia's freshwater fish. Marine and Freshwater Research, 62, 1082-1098.

Mouillot, D., Bellwood, D.R., Baraloto, C., Chave, J., Galzin, R., Harmelin-Vivien, M., Kulbicki, M., Lavergne, S., Lavorel, S., Mouquet, N., Paine, C.E.T., Renaud, J. \& Thuiller, W. (2013) Rare species support vulnerable functions in high-diversity ecosystems. PLoS Biology, 11, e1001569.

Mulholland, P.J., Fellows, C.S., Tank, J.L., Grimm, N.B., Webster, J.R., Hamilton, S.K., Martí, E., Ashkenas, L., Bowden, W.B., Dodds, W.K., McDowell, W.H., Paul, M.J. \& Peterson, B.J. (2001) Inter-biome comparison of factors controlling stream metabolism. Freshwater Biology, 46, 1503-1517.

Nipperess, D.A., Faith, D.P. \& Barton, K. (2010) Resemblance in phylogenetic diversity among ecological assemblages. Journal of Vegetation Science, 21, 809-820.

Palmer, M.A., Reidy Liermann, C.A., Nilsson, C., Flörke, M., Alcamo, J., Lake, P.S. \& Bond, N. (2008) Climate change and the world's river basins: anticipating management options. Frontiers in Ecology and the Environment, 6, 81-89.

Palmer, M.A., Lettenmaier, D.P., Poff, N.L., Postel, S.L., Richter, B. \& Warner, R. (2009) Climate change and river ecosystems: protection and adaptation options. Environmental Management, 44, 1053-1068.

Paradis, E., Claude, J. \& K., S., (2004) APE: analyses of phylogenetics and evolution in R language. Bioinformatics, 20, 289-290.

Pearson, R.G. \& Boyero, L. (2009) Gradients in regional diversity of freshwater taxa. Journal of the North American Benthological Society, 28, 504-514.

Peters, G. \& Theischinger, G. (2007) Die gondwanischen Aeshniden Australiens (Odonata: Telephlebiidae und Brachytronidae). Denisia, 20, 517-574.

Peters, G.P., Andrew, R.M., Boden, T., Canadell, J.G., Cias, P., Le Quéré, C., Marland, G., Raupach, M.R. \& Wilson, C. (2013) The challenge to keep global warming below 2 C. Nature Climate Change, 3, 4-6.

Petheram, C., Rustomji, P., McVicar, T.R., Cai, W., Chiew, F.H.S., Vleeshouwer, J., Van Niel, T.G., Li, L., Cresswell, R.G., Donohue, R.J., Teng, J. \& Perraud, J.M. (2012) Estimating the impact of projected climate change on runoff across the tropical savannas and semiarid rangelands of Northern Australia. Journal of Hydrometeorology, 13, 483-503.

Phillips, S.J., Williams, P., Midgley, G. \& Archer, A. (2008) Optimising dispersal corridors for the Cape Proteaceae using network flow. Ecological Applications, 18, 12001211.

Pinder, A.M., Halse, S.A., Shiel, R.J. \& McRae, J.M. (2010) An arid zone awash with diversity: patterns in the distribution of aquatic invertebrates in the Pilbara region of 
Western Australia. Records of the Western Australian Museum, 78, 205-246.

Pineda, E. \& Lobo, J.M. (2012) The performance of range maps and species distribution models representing the geographic variation of species richness at different resolutions. Global Ecology and Biogeography, 21, 934-944.

R Core Team (2013) R: a language and environment for statistical computing. R Foundation for Statistical Computing, Vienna, Austria.

Ricotta, C., Bacaro, G., Marignani, M., Godefroid, S. \& Mazzoleni, S. (2012) Computing diversity from dated phylogenies and taxonomic hierarchies: does it make a difference to the conclusions? Oecologia, 170, 501-506.

Robson, B.J., Chester, E.T. \& Austin, C.M. (2011) Why life history information matters: drought refuges and macroinvertebrate persistence in non-perennial streams subject to a drier climate. Marine and Freshwater Research, 62, 801810.

Rosauer, D. \& Moritz, C. (2013) Case Study 2: pleistocene stability and diversity of herpetofauna. Climate change refugia for terrestrial biodiversity: defining areas that promote species persistence and ecosystem resilience in the face of global climate change, pp. 77-96. National Climate Change Adaptation Research Facility, Gold Coast.

Rosauer, D., Laffan, S.W., Crisp, M.D., Donnellan, S.C. \& Cook, L.G. (2009) Phylogenetic endemism: a new approach for identifying geographical concentrations of evolutionary history. Molecular Ecology, 18, 4061-4072.

Sander, J. \& Wardell-Johnson, G. (2011) Fine-scale patterns of species and phylogenetic turnover in a global biodiversity hotspot: implications for climate change vulnerability. Journal of Vegetation Science, 22, 766-780.

Sauer, J., Domisch, S., Nowak, C. \& Haase, P. (2011) Low mountain ranges: summit traps for montane freshwater species under climate change. Biodiversity and Conservation, 20, 3133-3146.

Simaika, J.P., Samways, M.J., Kipping, J., Suhling, F., Dijkstra, K.-D.B., Clausnitzer, V., Boudot, J.-P. \& Domisch, S. (2013) Continental-scale conservation prioritization of African dragonflies. Biological Conservation, 157, 245254.

Slatyer, C., Rosauer, D. \& Lemckert, F. (2007) An assessment of endemism and species richness patterns in the Australian Anura. Journal of Biogeography, 34, 583-596.

Suhling, I.D.A. \& Suhling, F. (2013) Thermal adaptation affects interactions between a range-expanding and a native odonate species. Freshwater Biology, 58, 705-714.

Swenson, N.G. (2009) Phylogenetic resolution and quantifying the phylogenetic diversity and dispersion of communities. PLoS ONE, 4, e4390.

Theischinger, G. (2012) Classification of the Austroeschna group of genera including the introduction of four new subgenera (Glaciaeschna subgen. nov., Montiaeschna subgen. nov., Occidaeschna subgen. nov., and Petersaeschna subgen. nov.)(Anisoptera: Telephlebiidae). Libellula Supplement, 12, 29-48.
Theischinger, G. \& Endersby, I. (2009) Identification guide to the Australia Odonata. Department for Climate Change and Water NSW, Sydney.

Theischinger, G. \& Watson, J.A.L. (1984) Larvae of Australian Gomphomacromiinae and their bearing on the status of the Synthemis group of genera (Odonata: Corduliidae). Australian Journal of Zoology, 32, 67-95.

Thompson, R.M., Beardall, J., Beringer, J., Grace, M. \& Sardina, P. (2013) Mitigating impacts of climate change on stream food webs: impacts of elevated temperature and $\mathrm{CO} 2$ on the critical processes underpinning resilience of aquatic ecosystems.p. 136. National Climate Change Adaptation Research Facility, Gold Coast.

Thuiller, W., Lafourcade, B., Engler, R. \& Araújo, M.B. (2009) BIOMOD - A platform for ensemble forecasting of species distributions. Ecography, 32, 369-373.

Thuiller, W., Lavergne, S., Roquet, C., Boulangeat, I., Lafourcade, B. \& Araújo, M.B. (2011) Consequences of climate change on the tree of life in Europe. Nature, 470, 531-534.

Tucker, C.M., Cadotte, M.W., Davies, T.J. \& Rebelo, T.G. (2012) Incorporating Geographical and Evolutionary Rarity into Conservation Prioritization. Conservation Biology, 26, 593-601.

Turak, E., Marchant, R., Barmuta, L.A., Davis, J., Choy, S. \& Metzeling, L. (2011) River conservation in a changing world: invertebrate diversity and spatial prioritisation in south-eastern coastal Australia. Marine and Freshwater Research, 62, 300-311.

Watson, J.A.L. \& Theischinger, G. (1984) Regions of taxonomic disjunction in Australian Odonata and other freshwater insects. Odonatologica, 13, 147-157.

Watson, J.A.L., Theischinger, G. \& Abbey, H.M. (1991) The Australian Dragonflies: a Guide to the Identification, Distribution and Habits of Australian Odonata. CSIRO, Melbourne, Victoria.

Williams, S.E., Shoo, L.P., Isaac, J.L., Hoffmann, A.A. \& Langham, G. (2008) Towards an integrated framework for assessing the vulnerability of species to climate change. PLoS Biology, 6, 2621-2626.

WWF (2012) Living planet report 2012. WWF International, Gland, Switzerland.

Xenopoulos, M.A., Lodge, D.M., Alcamo, J., Märker, M., Schulze, K. \& Van Vuuren, D.P. (2005) Scenarios of freshwater fish extinctions from climate change and water withdrawal. Global Change Biology, 11, 1557-1564.

\section{SUPPORTING INFORMATION}

Additional Supporting Information may be found in the online version of this article:

Figure S1 Basal taxonomic phylogeny of Australian Odonata.

Figure S2 Full taxonomic phylogeny of Australian Odonata.

Table S1 List of Odonata within each threat category included in the analysis. 


\section{BIOSKETCH}

Alex Bush is a $\mathrm{PhD}$ graduate at Macquarie University, Sydney. He is studying the potential effects of climate change on stream macroinvertebrates, and the implications for conservation of freshwater ecosystems. He is a member of the Climate Change Ecology Workgroup led by Professor Lesley Hughes.
Author contributions: A.B. led data collection and modelling. A.B., G.T. and D.N. assembled the phylogeny and performed the analyses. A.B. wrote the first draft of the manuscript, and all authors contributed to revisions.

Editor: Chris Burridge 